\title{
A importância da odontologia para as gestantes: Uma breve revisão
}

\author{
The importance of dentistry for pregnant women: A brief review \\ La importancia de la odontología para las mujeres embarazadas: Una breve reseña
}

Mácio Emílio Caldeira da Silva

ORCID: https://orcid.org/0000-0003-1180-2634 Secretaria Municipal de Saúde de Machacalis, Brasil

E-mail: maciocs@yahoo.com.br

Ana Mécia Ribeiro Amador

ORCID: https://orcid.org/0000-0001-7756-4304 Secretaria Municipal de Saúde de Machacalis, Brasil Email: anamecia@yahoo.com.br

Dilceu Silveira Tolentino Júnior

ORCID: https://orcid.org/0000-0003-2435-7576 Universidade Federal dos Vales do Jequitinhonha e Mucuri, Brasil E-mail: dilceujunior@bol.com.br

\begin{abstract}
Resumo
Este artigo consiste em uma revisão da literatura que aborda a relação entre odontologia e gestação, tanto em aspectos fisiológicos - transmissibilidade de microorganismos orais da mãe para a criança - quanto em aspectos psicológicos percepção das condições de saúde bucal pelas gestantes. A gestação é um período especial na vida da mulher, no qual ela se torna mais receptiva à modificação de hábitos já adquiridos e à aquisição de novos comportamentos. Nesse contexto, é extremamente importante que o profissional conheça como a gestante percebe sua condição bucal, pois é a partir dessa percepção que ela irá moldar seu comportamento. Para os serviços de saúde, é a partir desse conhecimento que podem ser desenvolvidos programas educativos multidisciplinares que priorizem o pré-natal odontológico e garantam a precocidade da educação. É necessário que as gestantes desenvolvam uma gradual conscientização da importância de manter boas condições de saúde bucal, o que possibilitará reduzir a experiência de cárie na dentição de seus filhos.
\end{abstract}

Palavras-chave: Gestação; Cárie dentária; Percepção.

\begin{abstract}
This article consists of a literature review that addresses the relationship between dentistry and pregnancy, both in physiological aspects - transmissibility of oral microorganisms from the mother to the child - and in psychological aspects - perception of oral health conditions by pregnant women. Pregnancy is a special period in a woman's life, in which she becomes more receptive to the modification of habits already acquired and the acquisition of new behaviors. In this context, it is extremely important that the professional knows how the pregnant woman perceives her oral condition, as it is from this perception that she will shape her behavior. For health services, it is based on this knowledge that multidisciplinary educational programs can be developed that prioritize dental prenatal care and ensure early education. It is necessary that pregnant women develop a gradual awareness of the importance of maintaining good oral health conditions, which will make it possible to reduce the experience of caries in their children's teeth.
\end{abstract}

Keywords: Gestation; Dental caries; Perception.

\section{Resumen}

Este artículo consiste en una revisión de la literatura que aborda la relación entre la odontología y el embarazo, tanto en los aspectos fisiológicos - transmisibilidad de los microorganismos bucales de la madre al niño - como en los aspectos psicológicos - percepción de las condiciones de salud bucal por parte de la gestante. El embarazo es un período especial en la vida de la mujer, en el que se vuelve más receptiva a la modificación de hábitos ya adquiridos y la adquisición de nuevos comportamientos. En este contexto, es sumamente importante que el profesional conozca cómo la gestante percibe su condición bucal, ya que es a partir de esta percepción que ella moldeará su comportamiento. Para los servicios de salud, se basa en este conocimiento que se pueden desarrollar programas educativos multidisciplinarios que prioricen la atención odontológica prenatal y aseguren la educación temprana. Es necesario que las mujeres embarazadas desarrollen una conciencia paulatina de la importancia de mantener unas buenas condiciones de salud bucal, lo que permitirá reducir la experiencia de caries en los dientes de sus hijos.

Palabras clave: Gestación; Caries dental; Percepción. 


\section{Introdução}

A partir da introdução dos novos conceitos de promoção à saúde bucal, a abordagem preventiva de gestantes em função da sua saúde bucal e da saúde bucal dos seus futuros bebês tem sido tema de diversas publicações na área da saúde coletiva, da clínica odontológica geral e da odontopediatria (Torres, 1999; Brandão \& Silva, 2006). A gestação é um momento único para cada mulher. É o momento oportuno para se estabelecer relações saudáveis entre mãe e feto, é a fase em que as mulheres estão mais receptivas às informações e aquisição de novos hábitos (França \& Sobreira, 1999).

A metodologia mais utilizada na prática odontológica consiste em informar gestantes sobre as causas, condições em que lesões cariosas e doenças periodontais se desenvolvem e seus meios de transmissão (Konish, 1995). Na abordagem clínica da gestante, o objetivo é modificar a microbiota da mãe para uma menos patogênica, favorecendo assim, a saúde bucal da mãe e do bebê (Konish, 1995).

Apesar de propor e executar alguns programas preventivos para a gestante, a odontologia tem falhado em não adotar uma prática mais eficaz, direcionada, abrangente e acessível a este grupo populacional (Medeiros \& Ferreira, 1995). Os acompanhamentos pré-natais raramente incluem abordagens odontológicas, e quando o fazem, geralmente é sob forma de palestras, sem oportunidade para o controle e avaliação das condições de saúde bucal da gestante e do bebê, na fase pré-dentada (Medeiros, 1995).

As informações às gestantes são fragmentadas, não sistematizadas e pouco divulgadas, associando promoção de saúde bucal com presença de dentes e com eventos patológicos decorrentes do irrompimento dos mesmos (Medeiros, 1995). Assim, a gestante fica desprotegida e à margem do progresso atual do conhecimento científico no tocante às relações materno-fetais e suas implicações na saúde bucal (Medeiros, 1995).

Assim, o objetivo do presente trabalho foi sistematizar as informações de acordo com evidências científicas disponíveis na literatura sobre a gestação e odontologia e sensibilizar os profissionais acerca da importância da apropriação de uma abordagem multidimensional que atenda a demanda de saúde bucal da gestante, tanto em nível individual, quanto em nível coletivo.

\section{Metodologia}

Tratou-se de uma revisão narrativa realizada (Pereira et al., 2018), com caráter descritivo sobre os estudos que verificaram a importância da odontologia para as gestantes. Foram considerados elegíveis vários estudos conduzidos sobre a temática, dentre eles, destacam-se artigos científicos, livros, teses de doutorado e dissertações de mestrado. Foi pesquisado nas bases de dados MEDLINE, Embase e Web of Science sem restrição da data de publicação. As listas de referência dos estudos encontrados também foram verificadas para identificar estudos potencialmente elegíveis.

\section{Revisão da Literatura}

\subsection{Transmissão Vertical da Cárie Dental}

A ideia de que a mãe é a principal fonte de transmissão de microorganismos orais para os seus filhos foi inicialmente sugerida por Keyes (1960), através da utilização de modelos animais, onde verificou-se que o microorganismo responsável pelo início do processo carioso era transmitido vertical e diretamente entre as gerações, de indivíduos infectados para aqueles não infectados (Tanzer, 1995; Caufield, 1997). Um grupo de bactérias fenotipicamente semelhantes foi relacionado como sendo o principal componente bacteriano envolvido na cárie humana: são os Streptococos mutans (Caufield, 1993), S. mutans e em menor extensão, S. sobrinus são as principais espécies bacterianas que iniciam a cárie dental humana (Seow, 1998). 
Aaltonen (1991) investigou 284 crianças e relacionou a incidência de cárie que estas apresentaram com a incidência de cárie das mães e a frequência de contatos salivares destas mães com seus bebês até sete meses de idade. Analisou novamente as mesmas crianças na idade de 4 anos e constatou que a cárie dental ocorreu em $32 \%$ das crianças. O consumo frequente de comidas e bebidas açucaradas ingeridas pelas mães estava associado com um aumento na incidência de cárie materna. As mães que tiveram mais contatos salivares com seus filhos foram as que deram mais guloseimas a eles, comparadas com as que não tinham contatos salivares.

Considerando que a aquisição precoce dos estreptococos do grupo mutans é um fator de risco para o desenvolvimento de lesões cariosas nas crianças e que a transmissão desses microorganismos é dependente do nível de colonização apresentado pelas mães, Torres et al. (1999) analisaram a situação bucal de gestantes residentes na cidade de Bauru-SP. Foram amostradas 50 gestantes na faixa etária de 16 a 37 anos, de baixo nível socioeconômico e que faziam acompanhamento pré-natal no Núcleo de Assistência às Gestantes. Esses resultados demonstram que as gestantes albergam elevados níveis salivares de estreptococos do grupo mutans compatíveis com a transmissão precoce para os seus filhos. A detecção desses microorganismos, em contagens altas na saliva materna, irá favorecer a transmissão durante a irrupção da dentição decídua das crianças, sendo o desenvolvimento das lesões cariosas fortemente dependente do momento em que ocorreu a infecção e a precoce colonização geralmente associada com maior prevalência de cárie dentária (Torres et al., 1999).

Os estudos de Thorild et al. (2002) procuraram estabelecer a prevalência e a possível relação da colonização bucal por S. mutans em pares mãe - filho (crianças com 18 meses e 3 anos de idade) sustentando através de resultados o conceito da transmissão vertical, enfatizando a importância dos componentes dietéticos e justificando medidas preventivas primárias de ação direta nas mães com altos níveis de colonização. Klein et al. (2003) verificaram através do acompanhamento por 20 meses de 16 pares de mãe - filho, cujas crianças tinham inicialmente $6 \pm 2$ meses de vida, que as mães foram as principais fontes de infecção por S. mutans de seus filhos, havendo uma taxa de ocorrência de transmissão vertical de S. mutans e S. sobrinus em 81,3\% e $83,3 \%$, respectivamente entre os pares.

Dasanayake et al. (1993), após a aplicação de curta duração (5 minutos diários por 2 semanas) de fluoreto de sódio iodado $1 \%$ à dentição das mães na época em que geralmente ocorre a erupção do primeiro dente da criança, observaram uma significativa redução na contagem microbiana na saliva materna, no entanto, não foi verificada nenhuma influência na época da contaminação por Streptococus mutans e na experiência de cárie nas crianças, com relação ao grupo controle sem tratamento antimicrobiano. Concluíram que o tratamento experimental realizado nas mães foi de curta duração e muito precoce, uma vez que seus efeitos distanciaram-se muito do período referente à janela de infectividade relacionada à amostra do estudo. Sugerem, portanto que uma intervenção para a redução da transmissibilidade de potenciais patógenos entre pares, mãe e filho, pode ser mais efetiva se o tratamento antimicrobiano nas mães for realizado próximo à época em que as crianças são efetivamente colonizadas (janelas de infectividade).

Caulfield (1993) em seu estudo, demonstrou que as crianças experienciam um período de maior tendência em adquirir S. mutans. A este período ele chama de janela de infectividade e a idade média da aquisição inicial foi de 26 meses. Ressalta ainda que outra janela de infectividade esteja presente quando começarem a irromper os permanentes, entre 6 e 12 anos.

Zanata et al. (2003) avaliaram a efetividade de um programa de saúde bucal, iniciado durante a gestação, sobre a experiência de cárie de primigestas e seus filhos. Oitenta e uma gestantes, pertencentes a classes sociais pouco favorecidas, foram selecionadas com base no diagnóstico clínico de lesões de cárie ativas e foram divididas aleatoriamente em grupo controle ou experimental. As medidas preventivas foram aplicadas durante a gestação e 6 e 12 meses após o parto. Ambos os grupos receberam abordagem educativa e o grupo experimental recebeu adicionalmente tratamento com antimicrobianos e adequação bucal utilizando cimento ionômero de vidro. A prevalência de crianças cárie-ativas com a idade de dois anos foi de 33,3\% no 
grupo controle e 14,7\% no grupo experimental. O número médio de superfícies com lesões de cárie foi maior para as crianças do grupo controle quando comparadas às do grupo experimental $(6,3 \times 3,2)$.

\subsection{Percepção das Condições de Saúde Bucal}

A gestação é um período especial na vida da mulher, onde os cuidados com a saúde devem ser maiores e no qual ela torna-se mais sensível à adoção de novos hábitos e comportamentos. Por isso mesmo, talvez seja o momento mais adequado para analisar como ela percebe sua condição bucal, e a partir daí desenvolver programas educativos e/ou preventivos direcionados às suas reais necessidades (Silva et al., 2006). A importância de se entender como a pessoa percebe sua condição bucal está no fato de que seu comportamento é condicionado por essa percepção, pela importância dada a ela, pelos seus valores culturais e experiências passadas no sistema de saúde. Mesmo nos países mais desenvolvidos e que oferecem serviços odontológicos à sua população, uma grande parcela não os frequenta porque não tem percepção de sua necessidade (Silva et al., 2006).

Costa et al. reforçam a necessidade da implantação de programas preventivos - educativos, de maneira que a mãe/gestante possa atuar como agente multiplicador de informações que visem à promoção da sua saúde e toda a sua família. Para Costa et al. tais programas são importantes também para que a mãe/gestante desmistifique a atenção odontológica. Silva et al. (2006) afirmam que a avaliação da percepção das condições bucais da gestante é de fundamental importância para o planejamento e execução de serviços odontológicos voltados para a prevenção e controle desse grupo populacional, possibilitando o desenvolvimento de programas educativos específicos.

Avaliar o que é qualidade de vida entre mãe/gestantes torna-se importante fator definidor das políticas de saúde neste grupo (Abreu et al., 2002). A OMS (Organização Mundial de Saúde) define qualidade de vida como a percepção do indivíduo, de sua posição na vida, no contexto da cultura e do sistema de valores em que vive e em relação aos seus objetivos, expectativas, padrões e preocupações (Whoqol, 1995). Segundo Reisine (1988), na qualidade de vida, três dimensões são consideradas importantes: capacidade funcional (funções sociais, físicas, emocionais e intelectuais), percepção de bem-estar (satisfação com a vida e condições de saúde) e sintomas físicos (de doenças). Sob essa perspectiva, Abreu et al. (2002) objetivaram identificar e analisar as representações sociais do processo saúde-doença bucal entre mães e gestantes no meio rural de Itaúna-MG. Participaram do estudo, 29 mães, dentre as quais, algumas gestantes e puérperas. Através da abordagem qualitativa e de entrevistas semi-estruturadas, pôde-se avaliar como as condições de saúde bucal interferem na qualidade de vida da família. O discurso dominante das entrevistadas revelou que o adoecimento bucal está associado às normas de higiene e dietéticas, ou seja, saúde bucal não é considerada um estado, mas a atividade de cuidar do corpo (Paixão et al., 1995).

Brandão et al. (2006), verificaram a relação entre cárie precoce, variáveis socio-comportamentais e percepção pessoal dos pais sobre quem ou o que controla a determinação de eventos na vida, incluindo atitudes, expectativas e crenças no aprendizado. Foram envolvidas 110 crianças de 24 a 35 meses de idade em Araraquara-SP. Um questionário foi respondido pelas mães, cujo conteúdo incluía informações referentes às características socioeconômicas, comportamentos e atitudes relacionadas à saúde bucal da criança. Tendo em vista que a cárie precoce se desenvolve inicialmente em superfícies lisas, facilmente acessíveis à rotina de escovação, os níveis de higiene bucal têm sido associados ao risco de cárie. Neste sentido, a presença de biofilme, em incisivos superiores, tem sido considerada como fator de risco para a cárie dentária. A justificativa para tal ocorrência está no fato de a criança adquirir seu próprio hábito de escovação e uso do fio dental através da observação direta e cópia do comportamento da mãe.

\subsection{Saúde Bucal da Gestante}

A gestação representa uma experiência humana complexa que envolve uma dimensão social, na qual há a influência de diversos fatores externos, e outra biológica, em que é necessário o equilíbrio entre as condições orgânicas para o desenvolvimento 
do feto e o sistema imunológico da mãe (Barbieri et al., 2000). Offenbacher et al. (1996; 1998) descreveram um mecanismo biológico através do qual a doença periodontal da gestante pode contribuir para a ocorrência de parto pré-termo e/ou baixo peso ao nascer, uma das principais causas de mortalidade infantil. Tal estudo demonstrou que a presença de doença periodontal resulta em um risco 7,5 vezes maior de partos prematuros. Mencionam também que a infecção periodontal pode ser responsável por aproximadamente $18 \%$ dos casos de partos prematuros, sendo, portanto, um fator de risco mais forte do que o hábito de fumar ou o consumo de álcool. Estudos posteriores confirmam esta associação.

Cruz et al. (2005) realizaram um estudo do tipo caso-controle com 302 mulheres, sendo 102 mães de nascidos vivos de baixo peso (grupo caso) e 200 mães de nascidos vivos com peso normal (grupo controle). 57,8\% dos casos apresentavam doença periodontal contra apenas 39\% dos controles; $13,7 \%$ dos casos e 7,5\% dos controles portadores de doença periodontal apresentavam-na sob a forma generalizada. Ambos os resultados mostraram diferença estatisticamente significante. Na análise final, verificou-se que entre os portadores da doença, a chance do filho apresentar baixo peso ao nascer era cerca de duas vezes maior que entre aquelas sem a doença. Constatou-se também que mães com nível de escolaridade menor ou igual a quatro anos de estudo e portadores da doença periodontal, tiveram chance quatro vezes maior de ter filho de baixo peso ao nascer, quando comparadas àquelas sem essa patologia.

Em estudo recente, Garcia-Godoy et al. (1998 apud França \& Sobreira, 1999), avaliaram durante 30 meses, a efetividade de um regime cárie-preventivo. A técnica consistia em bochechos diários com fluoreto de sódio a 0,05\% e clorexidina a $0,12 \%$. O objetivo era baixar os níveis de $S$. mutans em mulheres grávidas e, subsequentemente, inibir o crescimento de bactérias em seus filhos. Os resultados mostraram que o tratamento reduziu consideravelmente os níveis de tais bactérias nas mães e retardou a colonização de bactérias nas suas crianças em aproximadamente quatro meses.

Konish (1995) afirma que o nível de saúde bucal da mãe tem relação com a saúde bucal da criança. Os pais, particularmente as mães, determinam em grande parte os hábitos que os filhos adotarão. Segundo Freire et al. (2000), os profissionais de saúde bucal são os agentes que criam as normas e, portanto, desempenham um importante papel na transmissão destas às mães, que por sua vez as interpretam e transmitem à criança. Blinkhorn (1981) afirma que se hábitos saudáveis são ensinados em idade precoce, as ações educativas em saúde a serem implantadas tardiamente podem se basear no esforço de rotinas já estabelecidas. Desta forma, a população-alvo para os programas de educação em saúde bucal que têm como objetivo, estabelecer, ao invés de modificar rotinas, são as mães de crianças jovens e até mesmo as gestantes. Freire (2000) afirma que membros da equipe de cuidados primários à saúde, incluindo médicos generalistas, obstetras, pediatras, enfermeiros, nutricionistas e agentes de saúde, que estão numa excelente posição para discutir o problema da cárie antes da primeira visita ao dentista, influenciam a saúde bucal da gestante e do recém-nascido. Sob esta perspectiva, Sheiham (1992) afirma que o trabalho em equipe constitui a abordagem mais adequada para a promoção de saúde bucal, utilizando-se pessoal não-odontológico, através da integração entre saúde bucal e saúde geral.

\section{Resultados e Discussão}

A literatura relata que os Streptococos mutans apresentam um período ideal para sua efetivação. O clássico estudo de Caufield et al. (1993) indica que os Streptococos mutans são transmitidos em um período definido de tempo, denominado janela de infectividade, que pode se alterar de acordo com as características epidemiológicas, sociais e culturais da população estudada (Alaluusua, 1991; Caufield, Cutter \& Dasanayake, 1993; Horowitz, 1998).

Os estudos para o conhecimento das vias de infecção por estreptococos cariogênicos sugeriram que a via mais provável de transmissão dessas bactérias nos pares mãe-filho (Köhler \& Bratthal, 1978; Van Houte, Yanover \& Brecher, 1981; Köhler, Bratthal \& Krasser, 1983; Zickert et al., 1983; Köhler, Andréem \& Jonsson, 1984; Brown, Junner \& Liew, 1985; Alaluusua, Myllarniemi \& Kallio, 1989: Matee et al., 1992; Aaltonen \& Tenovuo, 1994). 
Em um estudo epidemiológico realizado em crianças brasileiras (Mattos-Graner et al., 1998), verificou-se que a colonização precoce comparada ao período uma vez descrito, sugerindo uma antecipação da janela de infectividade, o que está de acordo com estudos que relatam a iniciação da cárie dentária em idades anteriores à abertura da janela de infectividade (Mohan et al., 1998; Mattos-Graner et al., 1998; Wan et al., 2003), já que a presença de infecção bacteriana, embora não suficiente, é necessária para a iniciação da doença (Burt et al., 1983; Carlsson, Olsson \& Bratthall, 1985; Li, Wang \& Caufield, 2000; MattosGraner et al., 2001). Esta precocidade da aquisição foi também relatada por vários estudos (Matsuda et al., 1979; Wan et al., 2003).

Streptococos mutans não são normalmente encontrados livres na natureza. É provável que os recém-nascidos sejam infectados por indivíduos com elevados índices de Streptococos mutans em sua cavidade bucal que têm contato frequente com a criança (Alaluusua, 1991). Contatos salivares diretos ou indiretos durante as atividades diárias proporcionam a repetida transferência de bactérias entre as pessoas, constituindo uma importante rota para a colonização bucal bacteriana (Könönen, 2000). Diversos estudos sugerem que a mãe é a principal fonte de infecção infantil de tais microorganismos, havendo uma relação diretamente proporcional entre a magnitude da contagem salivar materna e o potencial de infecção de seu filho (Berkowitz, Turner \& Green, 1980; Wan et al., 2001; Caufield, 1997).

Aaltonen (1991) observou em seu estudo, que apenas $25 \%$ das crianças que tiveram contatos salivares frequentes com mães de alto índice de cárie, tiveram cárie. Porém, estas crianças possuíam maior risco de desenvolver a doença. Cárie dental foi mais frequente em dois grupos de crianças, daquelas, cuja incidência de cárie materna foi baixa e contatos salivares mais próximos (40\%) e as de incidência de cárie materna alta e contatos raros (45\%). A situação mais favorável foi no grupo cuja incidência de cárie foi baixa e os contatos salivares foram baixos. Os resultados deste estudo deram suporte à teoria de que a incidência de cárie materna e contatos salivares com crianças são relacionados com imunidade à cárie dental.

Klein et al. (2003) e Emídio et al. (2003) em seu estudo - acompanhamento por 20 meses de 16 pares de mãe-filho concluíram que as mães foram as principais fontes de infecção por Streptococos mutans de seus filhos e que não houve transmissão horizontal entre as crianças que compartilhavam a mesma sala de uma das EMEIş de Piracicaba-SP. Além disso, sugeriram que além das mães, há outras fontes alternativas de transmissão. O conhecimento relacionado à etiologia da doença transmissível cárie dentária e o papel da mãe nesta transmissão possibilitou a compreensão de que a redução dos níveis de microorganismos orais maternos, durante o período de erupção dos dentes decíduos, influi consideravelmente na colonização da microbiota oral da criança e em suas futura experiência de cárie (Köhler, Andréen \& Jonson, 1984; Köhler \& Andréen, 1994; Dasanayake et al., 1993; Soderling et al., 2000; Isokangas et al., 2000; Dasanayake et al., 2002).

Torres et al., (1999) em análise da situação bucal de 50 gestantes da cidade de Bauru, verificaram uma correlação dos níveis de infecção na relação mãe-filho, através da demonstração de idêntico perfil entre ambos, dando suporte à noção de transferência a partir das mães, o que sugere que a transmissão do microorganismo está provavelmente confinada dentro de discretos pareamentos familiares. Tais resultados confirmaram os achados de Köhller; Bratthall (1978) que observaram correlação entre o grau de infecção com experiência de cárie, ou seja, elevadas contagens estavam associadas com maior risco à cárie dentária, incluindo lesões em superfície lisa. Os resultados obtidos mostraram que, entre as gestantes selecionadas, $8(16 \%)$ apresentaram 1.10 UFC/ml (Unidade Formadora de Colônia por mililitro), 12 (24\%), 5.10 UFC/ml e 10 (20\%), 2,5.10 UFC/ml, favoráveis à precoce transmissão para suas crianças, o que indica a necessidade de desenvolver-se um programa preventivo específico destinado às gestantes, visando a prevenção da transmissibilidade de bactérias cariogênicas a seus futuros filhos.

Em sua análise, Zanata observou que o incremento da cárie na dentição da mãe apresentou correlação significativa com a incidência de cárie na dentição das crianças. Tais dados suportam a evidência de associação entre cárie na primeira infância e a influência significativa de fatores maternos. 
Os resultados dos estudos de Cruz et al. (2005) indicam a existência de associação entre doença periodontal materna e baixo peso ao nascer e que seu efeito foi potencializado pelo baixo nível de escolaridade materna. Tais achados mostram-se consistentes quando comparados com os de autores que investigaram esta associação (Offenbacher et al., 1996, 1998; Jeffcoat et al., 2001; Lopez et al., 2002; Braz et al., 2000).

O encontro da sinergia entre baixa escolaridade e doença periodontal materna pode ser explicado pela maior frequência de higiene bucal deficiente praticada no período gestacional pelas mães com baixo nível de escolaridade. A ineficiência de tal prática ativaria, portanto, a doença periodontal, tornando-a ainda mais deletéria ao equilíbrio materno-fetal. Os resultados do presente estudo representam mais uma evidência a favor da hipótese da associação entre a doença periodontal e baixo peso ao nascer. No entanto, alguns fatores subjacentes ambientais e genéticos podem atuar conjuntamente, colocando a gestante sob o risco da doença e do baixo peso ao nascer, sem indicar relação de causa e efeito entre estas condições (Slots, 1998).

Também é plausível a existência de outras variáveis não pesquisadas, a exemplo de infecções em outros sítios, que poderiam resultar na doença e baixo peso (Cruz et al., 2005). Portanto, considerando os presentes achados, aliados àqueles encontrados na literatura nessa linha de pesquisa, deve-se reconhecer que estudos futuros ainda são necessários no sentido de determinar o impacto da condição periodontal na ocorrência de baixo peso ao nascer (Cruz et al., 2005).

Há uma relação entre percepção dos pais, cárie precoce e variáveis sociocomportamentais. Nesse contexto, o estudo de Brandão et al. (2006) permitiu identificar uma associação entre escolaridade paterna e cárie precoce, sendo tal fato semelhante ao observado por Fraiz (1993) e Walter (1987). Algumas hipóteses poderiam explicar tal associação: de acordo com Teitler (1999), o pai, numa visão mais recente, deixou de ser retratado unicamente como provedor, e sim como elemento crítico regulador - chave da instituição social família. Possuindo este melhor nível de escolaridade, teria aumentada a probabilidade de maior e melhor acesso a informações, atividades sócio culturais, melhor nível de autocuidado, podendo tais fatores refletir de forma positiva nos demais membros da família.

Mas os resultados também demonstram que a criança adquire hábito de escovação e fio dental, mediante observação direta e cópia do comportamento materno. Reflexos disso são os resultados que indicaram que quanto mais positiva a atitude da mãe com sua saúde bucal, menor foi a experiência de cárie; e quanto mais positiva sua atitude com a saúde bucal de seu filho, menor foi a experiência de cárie e melhor o nível de higiene bucal do mesmo. O referido estudo observou ainda que quando os pais receberam orientação sobre saúde bucal, ocorreram melhores níveis de higiene bucal, redução no nível de gengivite e manutenção desses resultados por maior período de tempo.

O saber feminino sobre o cuidado em saúde é construído socialmente, sendo influenciado pelo seu contato com os serviços de saúde, sua própria experiência no âmbito doméstico, transmissão de conhecimentos por antepassados e através dos meios de comunicação (Tezoquipa et al., 2001). Conflitam-se situações antagônicas: de um lado, o trabalho de cuidar, atividade inerente ao ser humano; do outro, as dificuldades impostas pela sociedade para a realização de tais atividades. No entanto, a prática de atividades educativas em saúde de cunho problematizador, e que consigam fazer um elo entre o trabalho de cuidar e os aspectos sociais, por ser um caminho para a solução de tais questões (Roux, 1994; Kemm, 2003; Pereira, 2003).

O trabalho de Abreu et al. (2002), cujo objetivo foi identificar e analisar as representações sociais do processo saúdedoença bucal entre mães e gestantes de Itaúna-MG, revelou que as entrevistadas ainda relacionam saúde com a utilização da tecnologia médica (medicamento) ou do serviço de saúde. Este fato mostra que a população se apropria do modelo tido como hegemônico na área da saúde para o qual o ser humano é considerado uma máquina e a doença, um mau funcionamento dos mecanismos biológicos (Abreu et al., 2002).

O papel do profissional, nesta lógica mecanicista, consiste em intervir física ou quimicamente, para consertar um defeito de funcionamento dessa "máquina" (Capra, 1989). Observou-se também que a cárie dentária afeta a maioria das entrevistadas e 
os seus filhos também. Assim, a doença é, para a maioria dos sujeitos, uma experiência inevitável. Esse achado confirma outros estudos (Kwan \& Holmes, 1999; Nations \& Nuto, 2002).

Em relação ao processo saúde-doença no âmbito de famílias, alguns autores colocam claramente a liderança da mãe nessas questões (Pordeus, 1991; Tezoquipa et al., 2001; Fernandes, 2002). Através da análise realizada, observou-se que as mães apresentam uma grande preocupação com a saúde bucal atual, bem como o impacto que essa terá no futuro do filho. As entrevistadas parecem não querer para os seus filhos as mesmas experiências que elas consideram negativas. Segundo Vicente (1998), quando um filho é gerado, há uma modificação na identidade dos genitores. Um imaginário repleto de esperança é construído pelos pais. O mesmo autor afirma que somente um estado de extrema miséria ou incerteza (presente, por exemplo, em uma guerra) pode retirar das pessoas o sonho de um futuro melhor para os seus filhos.

Cavalini (2000) afirma que os pais transmitem aos filhos suas fantasias, seus conhecimentos e suas experiências, moldando-os de acordo com suas condições psíquicas e com o grau de maturidade em que se encontram. $\mathrm{O}$ estudo destacou a liderança feminina nas questões da saúde em uma família. Greenwood e Cheers (2003) afirmam que existe na sociedade, uma forte cobrança em relação ao que se considera papel da mãe. Questões sanitárias têm sido identificadas como um atributo essencialmente feminino. A manutenção da saúde bucal é um desses papéis. As mães são fortemente cobradas em relação a essa obrigação social, sendo culpadas pelas condições de saúde bucal dos seus filhos (Wolf, 1998; Carneiro, 2001; Tezoquipa et al., 2001; Fernandes, 2002).

Abreu et al., (2002) afirmam que a dor de dente do filho, condição odontológica mais relatada pelas entrevistadas como fonte de problemas bucais, gera ansiedade, frustrações e, consequentemente, pode repercutir na qualidade de vida das mães. Santos et al. (2001) avaliaram o cotidiano de crianças hospitalizadas e revelaram sentimento de culpa nas mães, sendo que as mesmas gostariam de estar no lugar dos filhos. Nesse estudo, a dor de um filho gera sentimentos na mãe que confirmam a literatura consultada.

Silva et al. (2006) constatam que a mãe tem um importante papel na família, especialmente se a questão é sobre saúde, e que a gestação constitui um período no qual ela se encontra receptiva à incorporação de novas atitudes e comportamentos. O mesmo autor conclui ser extremamente importante conhecer como ela percebe sua condição bucal, pois é a partir dessa percepção que o indivíduo molda seu comportamento.

Para os serviços de saúde é a partir desse conhecimento que podem ser desenvolvidos programas educativos visando maior esclarecimento das pessoas envolvidas. Desta forma, o planejamento de ações coletivas deve levar em consideração não somente a eficácia da intervenção (Mota, 1999; Amaral et al., 2003), mas sobretudo as percepções que os grupos específicos têm da sua realidade. Atitudes educativas tradicionais que apenas informem, podem ser insuficientes para uma mudança de atitudes (Roux, 1994; Kemm, 2003; Pereira, 2003). O serviço de saúde bucal deve ter clareza dessas questões para que as atividades coletivas sejam organizadas dentro desse contexto.

Segundo Torres et al. (1999), há uma necessidade premente de se desenvolver e implantar um programa preventivo, com informações direcionadas às gestantes sobre o papel das principais bactérias cariogênicas e de seu próprio papel na transmissão; a importância do consumo do açúcar para o processo de início e progressão das lesões cariosas; as técnicas de higienização da cavidade bucal, envolvendo o controle químico e mecânico da placa dentária, conscientizando e motivando as gestantes para melhorar a condição de sua saúde bucal, a fim de criar hábitos que venham a ser aplicados nos seus bebês. Todo esse programa poderia ser desenvolvido durante a etapa dos exames pré-natais, quando as gestantes poderiam despender maior tempo para a correta adequação da cavidade bucal e desenvolver uma gradual conscientização da importância de manter boas condições de saúde bucal que possibilitarão diminuir ou protelar a infecção nas suas crianças e, consequentemente, reduzir a experiência de cárie dentária na dentição decídua de seus filhos (Torres et al., 1999). 
König (1994) considera que o profissional de saúde tem a função de motivar seus pacientes na tentativa de levar a uma consciente mudança de comportamento em direção às condutas de baixo risco. Sheiham (1992) afirma que para a efetividade do esforço educativo, torna-se necessária uma abordagem integrada e multiprofissional incluindo os meios de comunicação social, os profissionais de saúde em geral e o pessoal não odontológico.

Dentro desta perspectiva, França e Sobreira (1999) afirmam que é tarefa essencial daquele que se responsabiliza pela atenção odontológica da gestante, integrar-se às equipes que promovem, acompanham e controlam a saúde da gestante e do bebê. Destacam ainda o papel do cirurgião-dentista de trabalhar com as condutas necessárias para que as gestantes sejam responsáveis pela higienização bucal do seu futuro bebê e de reforçar, do ponto de vista odontológico, os cuidados e orientações pré-natais da equipe médica, com ênfase na amamentação e desmame, assumindo o comportamento das condições que vão influenciar a saúde bucal do seu futuro filho.

\section{Conclusão}

Durante a gestação, as transformações físicas, emocionais e psíquicas abrangem todo o organismo materno. Há uma correlação entre o grau de infecção da gestante (elevados níveis salivares de Streptococos mutans) e transmissão precoce de tais microrganismos para o seu filho. Daí a necessidade de que o profissional se aproprie de uma abordagem multidemensional qualificada sobre o conteúdo de saúde bucal da gestante para que esta se torne protagonista e potencializadora de forma assertiva da adoção de hábitos direcionados ao retardo da infecção primária pelos microrganismos cariogênicos e à redução da cárie dentária na dentição decídua de seus filhos.

Esperamos que a presente revisão venha agregar à discussão de trabalhos futuros referentes a esta temática que é tão oportuna e relevante para a sociedade atual, de forma a superar o grande desafio que é romper a cadeia epidemiológica da cárie dentária no ciclo gestacional.

\section{Referências}

Aaltonen, A. S., \& Tenovio J. (1994). Association between mother-infant salivary contacts and caries resistance in children: a cohort study. Pediatr Dent. 16(2):110-6.

Aaltonen, A. S. The frequency of mother-infant salivary close contacts and maternal caries activity affect caries occurrence in 4 year-old children. (1991). Proc. Finn Dent Soc. 87(3): 373-382.

Abreu, M. H. N. G., Pordeus, I. A., \& Moderna, C. M. (2005). Representações sociais de saúde bucal entre mães no meio rural de Itaúna (MG). Ciência saúde coletiva. 10(1):245-259

Alaluusua, S., Myllarniemi, S., \& Kallio, M. (1989). Streptococcus mutans infection level and caries in a group of 5 - year - old children. Caries Res. 23(3):1904.

Alaluusua, S. Transmission of mutans streptococci. (1991). Proc Finn Dent. Soc. 87(4):443-7.

Amaral, L. A., et al. (2003). Água de consumo humano como fator de risco à saúde em propriedades rurais. Revista de Saúde Pública. 37(4):510-514

Barbieri, M. A., Silva, A. A. M., Bettiol, H., \& Gomes, A. V. (2000). Fatores de risco para a tendência ascendente do baixo peso ao nascer em nascidos vivos de parto vaginal no Sudeste do Brasil. Rev. Saúde Pública. 34:596-602.

Berkowitz, R. J., Turner, J., \& Green, P. (1980). Primary oral infection of infants with streptococcus mutans. Arch Oral Biol. 25(4):221-4.

Blinkhorn, A. S. (1981). Dental preventive advice for pregnant and nursing mothers - sociological implications. Int Dent J. 31:14-22.

Brandão, I. M. G., Arcieri, R. M., Sundefeld, M. L. M., \& Moimaz, A. S. M. (2006). Cárie precoce: influência de variáveis sócio-comportamentais e do locus de controle da saúde em um grupo de crianças de Araraquara, SP. Cadernos de Saúde Pública, 22(6):1247-56.

Brown, J. P., Junner, C., \& Liew, V. (1985). A study of Streptococcus mutans levels in both infants with bottle caries and their mothers. Aust Dent J. 30(2):968.

Burt, B. A., Loesche, W. J., Eklund, S. A., \& Earnest, R. W. (1983). Stability of Streptococcus mutans and its relationship to caries in a child population over 2 years. Caries Res. 17(6):532-42

Capra, F. (1989). O ponto de mutação. A ciência, a sociedade e a cultura emergente: Cultrix. 
Carlsson, P., Olsson, B., \& Bratthall, D. (1985). The relationship between the bacterium Streptococcus mutans in the saliva and dental caries in children in Mozambique. Arch Oral Biol. 30(3):265-8.

Carneiro, A. M. O. (2001). Percepções em saúde bucal: valores, atitudes e problemas de um grupo de pessoas residentes na área rural de Brazilândia-DF. (Dissertação de mestrado). Belo Horizonte: Faculdade de Odontologia da Universidade Federal de Minas Gerais.

Caufield, P. W., Cutter, G. R., \& Dasanayake, A. P. (1993). Initial acquisition of mutans streptococci by infants: evidence for a discrete window of infectivity. J Dent Res. 72(1):37-45.

Caufield, P. W. (1997). Dental Caries - a transmissible and infectious disease revisited: a position paper. Pediat Dent. 19(8):491-8.

Cavalini, S. F. C. (2000). Um estudo sobre a implantação da relação pais - filhos na inibição intelectual [Dissertação]. São Paulo: Universidade São Marcos.

Costa, I. C. C., Marcelino, G., Berti, G. M., \& Saliba, N. A. (1998). A gestante como agente multiplicador da saúde. RPG Rev. Pos - Grad. 5:87-92.

Costa I. C. C., Saliba O., \& Moreira A. S. P. (2002). Atenção Odontológica à gestante na concepção médico-dentista-paciente: representações sociais dessa interação. RPG Rev. Pos-Grad. 9:232-43.

Cruz, S. S., Costa, M. C. N., Filho, I. S. G., Viana, I. P., \& Santos, C. T. (2005). Doença Periodontal materna como fator associado ao baixo peso ao nascer. Rev. Saúde Pública, 39(5):782-7.

Dasanayake, A. P., Caufiel, P. W., Cutter, G. R., \& Stiles, H. M. (1993). Transmission of mutans streptococci to infants following short term application of and iodine - Na F solution to mothers dentition. Community Dent Oral Epidemiol. 21(3):136-42.

Dasanayake, A. P., Wiener, H. W., Li, Y., Vermund, S. V., \& Caufield, P. W. (2002). Lack of effect of chlorhexidine varnish on Streptococcus mutans transmission and caries in mothers and children caries res. 36(4):288-93.

Emídio, T. C. S., Flório, F. M., Klein, M. I., Pereira, A. C., Hoffling, J. F., \& Gonçalves, R. B. (2003). Investigação genotípica de isolados de Streptococcus mutans provenientes de crianças que freqüentam creches In: $20^{a}$ Reunião anual da Sociedade Brasileira de pesquisa Odontológica - SBPqO, Águas de Lindóia. Revista de Pesquisa Odontológica Brasileira, 17:62.

Fernandes, M. L. M. F. (2002). Análise comparativa das percepções em saúde bucal de adolescentes grávidas e não grávidas: um ponto de partida para a promoção em saúde bucal. [Dissertação de mestrado]. Belo Horizonte: Faculdade de Odontologia, Universidade Federal de Minas Gerais.

Flório, F. M., \& Pereira, A. C. (2003). Alicerce para a promoção de saúde bucal - o início precoce. In Pereira AC \& Colaboradores, Odontologia em saúde coletiva: planejando ações e desenvolvendo saúde. $1^{\text {a }}$ Edição - Porto Alegre: Artmed.

Flório, F. M. (2003). Padrão de Colonização por Estreptococos grupo Mutans em crianças submetidas ou não a programa em Promoção de Saúde bucal. [Tese de Doutorado]. Piracicaba: Faculdade de Odontologia de Piracicaba da Universidade Estadual de Campinas.

França, A. M. L., \& Sobreira M. (1999). Cuidados para gestantes, visando a saúde bucal do futuro bebê. Subsídios para o profissional da área odon tológica. [Monografia]. Belo Horizonte: Associação Brasileira de Odontologia.

Fraiz, F. C. (1993). Estudo das características da utilização de açúcar através da mamadeira, do primeiro contato com o açúcar e do padrão de aleitamento em crianças de 0 a 36 meses [Dissertação]: Universidade de São Paulo.

Freire, M. C. M., Macedo, R. A., \& Silva, W. H. (2000). Conhecimentos, atitudes e práticas dos médicos pediatras em relação à saúde bucal. Pesq. Odont. Brasileira. 14(1):39-45.

Gonçalves, R. B., \& Flório, F. M. (2003). Ecologia microbiana da cavidade bucal. In Pereira AC \& Colaboradores, Odontologia em saúde coletiva: planejando ações e promovendo saúde. $1^{\text {a }}$ edição - Porto Alegre: Artmed.

Greenwood, G., \& Cheers, B. (2003). Womem, isolation and bush babies. Rural and Remote Health 2.

Horowitz, H. S. (1998). Research issues in early childhood caries. Community Dent Oral Epidemiol. 26(1Suppl):49-61.

Isokangas, P., Soderling, E., Pienihakkinen, K., \& Alanen, P. (2000). Occurrence of dental decay in children after maternal consumption of xylitol chewing gum, a follow-up from o to 5 years of age. J. Dent Res. 79(11):1885-9.

Jeffcoat, M. K, Geurs, N. C, Reddy, M. S., Cliver, S. P., Goldenberg, R. L., \& Hauth, J. C. (2001). Periodontal infection and preterm birth: results of a prospective study. J Am Dental Assoc. 132:875-80.

Kemm, J. (2003). Health education: a case for resuscitation. Public Health. 117(2):106-111.

Keyes, P. H. (1960). The infectious and transmissible nature of experimental dental caries. Arch oral Biolog. 1:304-20.

Klein, M. I., Flório, F. M., Höfling, J. F., Pereira, A. C., \& Gonçalves, R. B. (2003). Perfil de colonização da cavidade bucal de crianças por Streptococcus mutans e por Streptococcus sobrinus. In: 20ª Reunião Anual da Sociedade Brasileira de Pesquisa Odontológica - SBPqO, 2003; Águas de Lindóia. Revista de Pesquisa Odontológica Brasileira. 17:180.

Klein, M. I., Flório, F. M., Höfling, J. F., Pereira, A. C., \& Gonçalves, R. B. (2002). Transmission, diversity and estability of S. mutans genotypes: a longitudinal study in children. J Dent Res. 81 (spec iss B): 1345.

Kohler, B., Andreen, I., \& Jonsson, B. (1984). The effect of caries - preventive measures in mothers on dental caries and the oral presence of the bacteria Streptococcus mutans and lactobacilli in their children. Arch Oral Biol. 29(11):879-83. 
Kohler, B., \& Andreen, I. Influence of caries - preventive measures in mothers on cariogenic bacteria and caries experience in their children. (1994). Arch Oral Biol. 39(10):907-11.

Kohler, B., Bratthall, D., \& Krasse, B. (1983). Preventive measures in mothers influence the establishment of the bacterium Streptococcus mutans in their infants. Arch Oral Biol. 28(3):225-31.

Kohler, B., \& Bratthall, D. (1978). Intrafamilial levels of Streptococcus mutans and some aspects of the bacterial transmission. Scand J Dent Res. 86(1):35-42.

Konig, K. G. (1994). Implications of changes in caries prevalence on research. Int Dent J. 44(4 Supl):451-6.

Konish, F. (1995). Odontologia para gestantes. Rev. APCD. 49(1):27.

Könönen, E. (2000). Development of oral bacterial flora in young children. Ann Med. 32:107-12.

Kwan, S. Y. L., \& Holmes, M. A. M. (1999). An exploration of oral health beliefs and attitudes of Chinese in west Yorkshire: a qualitative investigation. Health Education Research. 14(4):453-460.

Leão, A., \& Sheiham, A. (1995). Relation between clinical dental status and subjective impacts on daily living. J Dent Res. 74:1408-13.

Li, Y., Wang, W., \& Caufield, P. W. (2000). The fidelity of mutans streptococci transmission and caries status correlate with breastfeeding experience among Chinese families. Caries Res. 34(2):123-32.

Lopez, N. J., Smith, P. C., \& Gutierrez, J. (2002). Periodontal Therapy may reduce the risk of preterm low birth weight in women with periodontal disease: a randomized controlled trial. J. periodontal. 73:911-24.

Masuda, N., Tsutsumi, N., Sobue, S., \& Hamda, S. (1979). Longitudinal Survey of the distribution of various serotypes of streptococcus mutans in infants. $J$ Clin Microbiol. 10(4):497-502.

Matee, M. I., Mikx, F. H., Maselle, S. Y., \& Van Palenstein Helderman, W. H. (1992). Mutans Streptococci and lactobacilli in breast-fed children with rampant caries. Caries Res. 26(3):183-7.

Mattos-Graner, R. O., Li, Y., Caufield, P. W., Duncan, M., \& Smith, D. J. (2001). Genotypie diversity of mutans streptococci in Brazilian nursey children suggests horizontal transmission. J Clin Microbiol. 39(6):2313-6.

Mattos-Graner, R. O., Zelante, F., Line, R. C. S. R., \& Mayer, M. P. A. (1998). Association between caries prevalence and clinical, microbiological and dietary variable in 1.0 to 2.5 - years - old Brazilian children. Caries Res. 32:319-23.

Medeiros, U. V. (1993). Atenção odontológica para bebês. Revista Paulista de Odontologia. 6:18-27.

Medeiros, U. V., \& Ferreira, N. A. (1995). Prevenção à cárie através da dieta. Revista Brasileira de Odontologia. 52(2):42-46.

Mohan, A., Morse de, O., Sullivan, D. M., \& Tinanoff, N. (1998). The relationship between bottle usage / content, age, and number of teeth with mutans streptococci colonization in 6 - 24 month - old children. Community Dent Oral Epidemiol. 26(10):12-20.

Motta, S. Saneamento. (1999). In Rouquayrol, M. Z. Epidemiologia e saúde. (5ª Edição): Medsi.

Nations, M. K. \& Nuto, S. A. S. (2002). “Tooth Worms”, poverty tattoos and dental care conflicts in Northeast Brazil. Social Science and Medicine. 54(2):229244.

Offenbacher, S., Katz, V., Fertik, G., Collins, J., Boyd, D., Maynor, G., et al. (1996). Periodontal infection as a possible risk fator for preterm low birth weght. J Periodontal. 67:1103-13.

Offenbacher, S., Jared, H. L., O’ Reilly, P. G., Wells, R. S., Salvi, G. E., Lawrence, H. P., et al. (1998). Potential pathogenic mechanisms of periodontitis associated pregnancy complications. ANN Periodontal. 3:233-50.

OMS. (1991). Levantamento epidemiológico básico de saúde bucal: manual de instruções. (3ª ed.): Livraria Editora Santos, $25-32$.

Paixão, H. H., Pordeus, I. A., \& Ferreira, E. F. (1995). Saúde e doença bucal: concepções e contradições. IV Encontro de Pesquisa da Faculdade de Odontologia da UFMG.

Pereira, A. L. F. (2003). Pedagogical approaches and educational practices in health sciences. Cadernos de Saúde Pública, 19(5):1527-1534.

Pereira, A. S., Shitsuka, D. M., Parreira, F. J., \& Shitsuka, R. (2018). Methodology of cientific research. [e-Book]. Santa Maria City. UAB / NTE / UFSM Editors.

Pordeus, I. A. (1991). Intra-family patterns of dental health status and behaviors. A study of Brazilian families. Tese de Doutorado. Univesity College of London, Londres.

Reisine, S. T. (1988). The impact of dental conditions on social functioning and the quality of life. Annual Review of Public Health, 9:1-19.

Rouquayrol, M. Z., \& Goldbaum, M. Epidemiologia, história natural e prevenção de doenças. In Rouquayrol, M. Z., \& Filho, N. A. (1999). Epidemiologia e saúde. (5 edição): $M e d$.

Roux, G. I. (1994). La prevencion de comportamientos de riesgo y la promocion de estilos de vida saluble em el desarrolo de la salud. $28(2)$ :223-233.

Santos, A. F., et al. (2001). O cotidiano da mãe com seu filho hospitalizado: uma contribuição para a enfermagem pediátrica. Escola Anna Nery. Revista de Enfermagem, 5(3):325-334. 
Research, Society and Development, v. 10, n. 6, e0810615515, 2021

(CC BY 4.0) | ISSN 2525-3409 | DOI: http://dx.doi.org/10.33448/rsd-v10i6.15515

Sheiham, A. (1992). The role of the dental team in promoting dental health and general ealth through oral health. Int Dent J. 42:223-228.

Seow, W. K. (1998). Biological mechanisms of early child hood caries. Community Dent Oral Epidemiol. 26(1 suppl):8-27.

Silva, S. R. C., Rosell, F. L., \& Júnior, A. V. (2006). Percepção das condições de saúde bucal por gestantes atendidas em uma unidade de saúde no município de Araraquara, São Paulo. Rev. Brás. Saúde Materno-Infantil, 6(4):405-410.

Slots, J. (1998). Casual or causal relationship between periodontal infection and non - oral disease. J Dental Res. 77:1764-5.

Tanzer, J. M. (1995). Dental caries is a transmissible infections disease: the keyes and Fitzgerald revolution. J Dent Res. 74(9):1536-42

Teitler, J. (1999). Father involvement, child health and maternal health behavior. New York: Columbia University School of Social Work.

Tezoquipa, I. H., Monreal, M. L. A., \& Santiago, R. V. (2001). El cuidado a la salud em el âmbito doméstico: inteacion social y vida cotidiana. Revista de Saúde Pública, 35(5):443-450.

Thorild, I., Lindau-Jonson, B., \& Twtman, S. (2002). Prevalence of salivary Streptococcus mutans in mothers and their preschool children. In J Pediatr Dent, 12(1):2-7.

Torres, S. A., Rosa, O. P. S., Akyosh, N., Silveira, A. M. M., \& Bretz, W. A. (1999). Níveis de infecção de streptococcus do grupo mutans em gestantes. Rev. Odont. Univ. São Paulo,13(3):225-231.

Van Houte, J., Yanover, L., \& Brecher, S. (1981). Relationship of levels of the bacterium Streptococcus mutans in saliva of children and their parents. Arch Oral boil. 26(5):381-6.

Vicente, C. M. (1998). O direito à convivência familiar e comunitária: uma política de manutenção do vínculo. In Kaloustian SM. Família B rasileira: a base de tudo. ( $3^{\mathrm{a}}$ ed): Cortez Editora - UNICEF.

Walter, L. R. F., Ferelle, A., Hokama, N., Pelanda, V. L. G., Franco, M. P. S., \& Iega, R. (1987). Cárie em crianças de 0 a 30 meses de idade e sua relação com hábitos alimentares. Enciclopédia Brasileira de Odontologia, 5:129-36.

Wan, A. K., Seow, W. K., Purdie, D. M., Bird, O. S., Walsh, L. J., \& Tudehope, D. I. (2003). A longitudinall study of streptococcus mutans colonization in infants after tooth eruption. $J$ Dent Res. 82(7):504-8.

Whoqol Group. (1995). The Word Health Organization Quality of Life Assesment (WHOQOL): position paper from the world Health Organization. Social Science and Medicine, 41(10):403-409.

Wolf, S. M. R. (1998). O significado psicológico da perda dos dentes em sujeitos adultos. Revista da APCD, 52(4):307-315.

Zanata, R. L., Navarro, M. F. L., Pereira, J. C., et al. (2003). Effect of caries preventive measures directed to expectant mothers on caries experience em their children. Braz. Dent. J. 14(2):75-81. 